\title{
EL ESTADO REGIONAL ITALIANO, ENTRE LA ACTUACIÓNO LA MODIFICACIÓN DE LA REFORMA CONSTITUCIONAL VIGENTE
}

\author{
CARLOS ORTEGA SANTIAGO \\ Profesor de Derecho Constitucional \\ Universidad de Valladolid
}

\section{SUMARIO}

I. Introducción.

II. La jurisprudencia de la Corte Constitucional: La prevalencia.

III. Los materias concurrentes.

IV. Los principios de subsidiariedad y de colaboración leal, y los poderes sustitutivos del Estado.

V. El interés nacional.

VI. Algunos de los contenidos de la propuesta de ley constitucional de reforma.

\section{INTRODUCCIÓN}

En octubre de 2003 el Gobierno italiano presentó en el Senado un proyecto de ley de reforma constitucional en el que se introducían cambios en toda la Parte II de la Constitución, aquélla referida a la organización del Estado. En su tramitación, esta propuesta se ha visto sometida al complicado proceso parlamentario italiano de la doble lectura, y ha sido objeto de relevantes variaciones de contenido durante el iter legislativo. Todo parece indicar que la reforma se encamina hacia su conclusión exitosa antes de las elecciones generales de 2006, puesto que el texto resultante de las lecturas parlamentarias ya no es susceptible de revisión y sólo queda que se someta a la aprobación de ambas Cámaras en segunda votación.

No obstante, es muy probable que, tras su aprobación en sede parlamentaria, el texto deba someterse a referéndum popular, ya que sólo cuenta con el 
beneplácito de la mayoría parlamentaria de Gobierno, y un quinto de los miembros de una de las Cámaras podría solicitar la celebración de dicho referéndum (art. 138 de la Constitución italiana, solicitud que también corresponde a quinientos mil electores o cinco Consejos regionales), referéndum que sólo se evitaría si la propuesta contara con los votos favorables de dos tercios de los miembros de cada Cámara, hipótesis harto improbable.

En la práctica, esta reforma constitucional en tramitación no pretende completar las que se realizaron en 1999 y en 2001, que se ocuparon del Título V de la Constitución italiana, dedicado a la organización territorial del poder, y que dejaron pendientes algunas alteraciones constitucionales esenciales para hacer efectivo el nuevo Estado regional previsto en las reformas (significadamente, la nueva organización del Senado). Por el contrario, la nueva propuesta de reforma incide también en el Título $\mathrm{V}$ de la Constitución, entre otros motivos porque aquellas reformas fueron aprobadas por una mayoría parlamentaria diferente a la que ahora sustenta la modificación constitucional.

Con lo cual, se plantea un problema de calado que se concreta en una doble dirección. Por una parte, el desarrollo legislativo de estas reformas (la vigente y la proyectada), que no cuentan con el consenso de la mayoría y de la oposición, está supeditado a la continuidad de la misma mayoría parlamentaria tras la celebración de elecciones. Por otro lado, eso es lo que explica, en relación con la reforma de 2001, que ésta haya sido objeto de concreción fundamentalmente por vía jurisprudencial, a través de la actividad de la Corte constitucional. Pero toda esa doctrina que ha ido consolidando la Corte, en casi cuatro años de vigencia de la nueva forma de organización territorial del poder, deberá redefinirse si la reforma constitucional en tramitación entra definitivamente en vigor, ya que altera alguno de los contenidos esenciales del texto constitucional vigente.

La configuración jurisprudencial de la organización territorial del poder prevista en las reformas constitucionales de 1999 y de 2001 que ha venido realizando la Corte italiana es de gran interés, puesto que ha sido construida a partir de un entramado novedoso de criterios hasta ahora ajenos al ordenamiento constitucional de ese país, a la vez que ha exigido el abandono de antiguos principios ya sin eficacia tras la reforma. Esto se ha puesto de manifiesto, de manera especial, en el ámbito de los conflictos competenciales entre el Estado y las regiones, en cuya resolución el Alto tribunal italiano ha ido delimitando el alcance de las competencias propias de los diversos entes territoriales y el modo en que se articulan las mismas, a partir de los nuevos preceptos constitucionales sobre la materia.

En esta crónica haremos un repaso a las líneas esenciales que han informado la jurisprudencia de la Corte en este sentido, teniendo en cuenta, además, que en estos últimos años se está consolidando el carácter de la jurisdicción constitucional italiana como jurisdicción de conflictos, en detrimento de la que había venido siendo su configuración habitual, como juez de las leyes por vía incidental. El quantum de las decisiones del Alto tribunal italiano que se han ocupado tras la reforma de controversias competenciales, ya tuvieran por 
objeto leyes del Estado, Estatutos o leyes regionales, es buena muestra de la profundidad y de la importancia que reviste, desde la perspectiva del Derecho constitucional, la nueva organización territorial del poder propia del ordenamiento de este país.

Junto a este análisis del Derecho vigente, se hará preciso realizar unas breves consideraciones acerca de las modificaciones más relevantes que se incorporarían al Título $\mathrm{V}$ de la Constitución de prosperar la propuesta de reforma constitucional en tramitación en el Parlamento italiano. Este referente se hace preciso puesto que esa propuesta se explica desde un doble objetivo: Por una parte, trata de solventar algunas de las deficiencias, que se detectaron tempranamente en sede doctrinal, en cuanto al reparto competencial previsto en el art. 117 de la Constitución italiana tras la reforma de 2001 (reduplicación de títulos competenciales en el ámbito de las materias exclusivas y concurrentes; falta de previsión de determinados títulos que deberían ser propios de la competencia exclusiva del Estado como las redes estratégicas de transporte y navegación, o la producción, transporte y distribución de la energía; o la inexistencia de una cláusula legitimadora de la intervención unificadora del Estado en el ámbito de las competencias regionales).

Por otra parte, porque la reforma introduce mecanismos nuevos de intervención estatal (o, mejor, reintroduce mecanismos antiguos, como el interés nacional, del que hablaremos después) cuya trascendencia y alcance le convierte en un principio constitucional con capacidad para determinar, incluso, la forma territorial del Estado y el alcance de la autonomía de los entes territoriales.

En este sentido, no cabe duda de que la propuesta de reforma que está tramitando el Parlamento italiano incorpora otros contenidos de gran interés junto a esta modificación del Título $\mathrm{V}$, como ocurre con la formulación de una nueva forma de gobierno basada en la consolidación de un Premierato sólido; o con la nueva organización del poder legislativo y de las funciones asignadas al nuevo Senado federal, que suponen el fin del tradicional bicameralismo paritario italiano. Puede decirse que, en estos dos ámbitos, la reforma propuesta viene a establecer una nueva Constitución, al menos por lo que se refiere a las relaciones entre los poderes legislativo y ejecutivo; de ahí que parezca más adecuado y efectivo tratar esos contenidos en un futuro, no como Constitutione ferenda sino ya como Constitutione data.

\section{LA JURISPRUDENCIA DE LA CORTE CONSTITUCIONAL: LA PREVALENCIA}

Centrándonos, por ello, en la organización del Estado regional, se hace necesario comenzar recordando algo que ya se indicó en anteriores crónicas, que la reforma de 2001 incorporó al art. 117 de la Constitución italiana un sistema de reparto de competencias genuinamente federal, con un listado con las materias de competencia (legislativa y reglamentaria) exclusiva del Estado y 
otro con aquellas materias de legislación concurrente entre el Estado y las regiones; el resto de materias no previstas en esos listados se configuran como materias legislativas (exclusivas) de las regiones en virtud de la cláusula residual, regiones que ostentan también las competencias reglamentarias en estas últimas materias y en las concurrentes. Además, el Estado puede delegar su potestad reglamentaria en las regiones, mientras que el resto de entes territoriales (municipios, provincias y ciudades metropolitanas) disponen de potestad reglamentaria para organizar y desarrollar las funciones que les atribuya el ordenamiento jurídico.

La jurisprudencia constitucional en el ámbito de las competencias normativas regionales y estatales ha venido marcada por una tendencia que se podría resumir en la siguiente afirmación: "La Corte ha sido estatalista cuando ha debido serlo y ha sido regionalista cuando ha podido serlo". Pero lo que llama la atención, de modo especial, en las sentencias que ha dictado la Corte constitucional italiana como consecuencia de las numerosas cuestiones competenciales que han llegado a su conocimiento tras la reforma, es la virtualidad expansiva, a favor de la actuación estatal, que han desplegado determinadas cláusulas constitucionales, como ocurre con los poderes sustitutivos o con las materias competenciales transversales.

En la práctica, como ocurre en cualquier distribución territorial del poder ordenada a través de listas de materias, sobre los sectores de la realidad que son objeto de ordenación por parte de las normas pueden proyectarse diferentes títulos competenciales, de manera que queda a la decisión de los diferentes legisladores y, en último extremo, de la jurisdicción constitucional, determinar cuál de dichos títulos en los que podría subsumirse un determinado ámbito material es el competente para regular el mismo.

En el caso de la Corte constitucional italiana, ésta se sirve del que denomina criterio de prevalencia, pero con un sentido diferente al modo en que se configura en nuestro ordenamiento (aunque se utilice escasamente en la jurisprudencia de nuestro Tribunal Constitucional). Así, en los juicios con relevancia competencial que efectúa el Alto tribunal italiano, el primero de los pasos consiste en determinar las distintas materias donde podrían integrarse las disposiciones normativas impugnadas para, a partir de ahí, establecer "...cuál puede considerarse prevalente para atraer [a su ámbito de actuación] la totalidad de la disciplina normativa..." (Sentencia n. ${ }^{\circ} 151$ de 2005, entre las más recientes).

Según la Corte, es posible que sobre un determinado ámbito material concurran diversos títulos competenciales; pero aquí el término concurrencia se utiliza en sentido diferente al que tiene en el caso de las materias concurrentes, ya que describe una convergencia, un concurso de competencias (Sentencia n. ${ }^{\circ} 231$ de 2005), frente al que la Constitución no prevé un criterio de composición de las interferencias competenciales, a diferencia de lo que ocurre con las materias concurrentes (definidas expresamente así en el texto constitucional italiano y articuladas a partir de la legislación principialista del Estado-desarrollo legislativo regional, ex. art. 117.3, como se dirá después). 
En esos supuestos de confluencia, cuando "... no pueda determinarse la prevalencia cierta de un complejo normativo respecto de los otros, que baga dominante a la correspondiente competencia legislativa [estatal o regional], se debe recurrir al canon de la "leal colaboración", que impone a la ley estatal la predisposición de instrumentos adecuados de implicación de las regiones, para la salvaguardia de sus competencias" (Sentencia n. 50 de 2005). Colaboración leal que consiste, para estos supuestos de confluencia competencial, en términos similares a lo que ocurre en relación con el principio de subsidiariedad y los poderes sustitutivos del Estado —como se dirá después-, en la necesidad de que la legislación estatal prevea mecanismos de intervención regional (a través de acuerdos) en la actuación de esas materias.

\section{LAS MATERIAS CONCURRENTES}

Pero, como se acaba de apuntar, existen otra serie de criterios que sirven para resolver las diferentes controversias competenciales que puedan suscitarse entre el Estado y las regiones. En primer lugar, cuando se trata de materias concurrentes, la ley estatal será conforme con la Constitución si existe un título competencial estatal de este carácter y, al mismo tiempo, la regulación contenida en la norma legal estatal se limita a establecer la determinación de los principios fundamentales de la materia (que es lo propio de la legislación estatal en esa tipología de materias, según lo previsto en el párrafo tercero del art. 117 de la Constitución italiana).

Evidentemente, en estos supuestos el problema fundamental estriba en definir cuál ha de ser el alcance propio de esos principios fundamentales, como es de sobra conocido en nuestro ordenamiento en relación con las materias estructuradas a través de la normación básica del Estado-desarrollo legislativo de las Comunidades Autónomas. Además, el carácter principialista del ámbito de actuación estatal provoca que, en estos supuestos, la linde entre la actuación permitida y la vedada a la legislación del Estado sea más bien lábil, y que deba definirse a partir de criterios dúctiles como el de la proporcionalidad o el de la razonabilidad de las regulaciones que establezcan principios fundamentales en las materias concurrentes.

En último extremo, para garantizar la pervivencia de una regulación estatal unitaria que no comprima, al mismo tiempo, la legislación regional en estas materias, la Corte constitucional italiana ha ido delimitando una serie de criterios que, como se verá a continuación, no son extraños a la jurisprudencia consolidada de nuestro Tribunal Constitucional. Así, a pesar de que el nuevo sistema de reparto de competencias entre el Estado y las regiones ( $y$ las propias materias concurrentes) se han incorporado a la Constitución en 2001, estas últimas no han de esperar a que aquél dicte las correspondientes leyes estableciendo los principios fundamentales de dichas materias, sino que cabe la posibilidad de que el contenido de esos principios sea deducido de la legislación estatal an- 
terior, a falta de lo que la Corte denomina ley marco estatal (legge cornice statale) definidora de los referidos principios.

Esta deducción de los principios fundamentales de una determinada materia concurrente a partir de la legislación estatal previa a la reforma constitucional, puede actuar, al mismo tiempo, en favor del Estado, ya que la nueva legislación regional habrá de respetar los referidos principios. En palabras de la Corte constitucional, "La nueva formulación del art. 117.3, respecto a la vigente con anterioridad del art. 117.1, expresa la intención de una distinción más clara entre la competencia regional para legislar en estas materias y la competencia estatal, limitada a la determinación de los principios fundamentales de la regulación. Eso no significa, sin embargo, que los principios puedan derivarse unicamente de las leyes estatales nuevas, dirigidas expresamente a ese fin. Especialmente en la fase de transición del viejo al nuevo sistema de reparto de competencias, la legislación regional concurrente deberá desarrollarse con respeto a los principios fundamentales que se deriven en todo caso de la legislación estatal en vigor (Sentencia n. 282 de 2002, respecto del ámbito material de la tutela de la salud).

Por otra parte, en el supuesto de que una ley marco estatal se exceda en la determinación de esa regulación principialista y, simultáneamente, no exista una regulación legal regional que se ocupe de la materia objeto de la ley estatal que sobrepasa su ámbito competencial, la Corte constitucional se ha servido de la técnica de la inconstitucionalidad de la ley estatal con nulidad diferida, hasta que se establezca la legislación regional sobre esa materia y para evitar la falta de regulación sobre la misma (en la Sentencia 13 de 2004, en el ámbito material de la educación).

Por último, para la Corte constitucional una ley estatal en una materia concurrente será conforme con la Constitución, si ello es necesario para lograr que la regulación de un determinado valor u objetivo constitucional no se vea sometido a una disciplina legal fraccionaria en el territorio del Estado (Sentencia 361 de 2003). Esta identificación de la necesidad de una regulación unitaria sobre una determinada materia con la determinación de los principios fundamentales de la misma se explica, en buena medida, porque tras la reforma de 2001 la Constitución italiana no contiene ninguna cláusula de salvaguarda que conceda una competencia general a favor del Estado en determinadas circunstancias.

\section{LOS PRINCIPIOS DE SUBSIDIARIEDAD Y DE COLABORACIÓN LEAL, Y LOS PODERES SUSTITUTIVOS DEL ESTADO}

En directa relación con esta carencia del texto constitucional se encuentra el alcance habilitador de la actuación estatal que ha atribuido la Corte al principio de subsidiariedad previsto, tras la reforma de 2001, en dos preceptos de la Constitución con diferentes contenidos [el art. 118.1: "Las funciones administrativas se atribuyen a los municipios salvo que, para asegurar su ejercicio 
unitario, se confieran a las provincias, las ciudades metropolitanas, las regiones y el estado, con base en los principios de subsidiariedad, diferenciación y adecuación, y el art. 120.2: "El Gobierno puede reemplazar a los órganos de las regiones, de las ciudades metropolitanas, de las provincias y de los municipios (en determinados supuestos sobre los que se volverá después)... La ley define los procedimientos para garantizar que los poderes sustitutivos se ejerzan respetando el principio de subsidiariedad y el principio de colaboración leali.

Respecto del primer supuesto, en una de las sentencias que más aportaciones doctrinales ha originado (la 303 de 2003, referida a una legislación estatal sobre grandes obras públicas), la Corte considera que, en determinadas condiciones, el reparto de competencias previsto en la Constitución, en principio rígido y configurado a partir de un orden constitucional fuertemente imbuido de un pluralismo institucional, puede ser objeto de derogación para lograr un ámbito de ejercicio unitario por el Estado de competencias administrativas (de ejecución) en una materia vinculada a un título competencial concurrente como las grandes obras públicas; competencias de ejecución que en principio no corresponden al Estado, que ni siquiera dispone en las materias concurrentes de potestades reglamentarias.

A falta de una cláusula unitaria como la prevista en la Constitución alemana en relación con la legislación concurrente, o en Estados Unidos con la supremacy clause (según las alusiones expresas de la Corte en esa Sentencia), el principio de subsidiariedad de naturaleza administrativa previsto en el art. 118 de la Constitución italiana dispondría de la capacidad, incluso, de atraer la potestad legislativa estatal subsidiaria en esa materia, para que la actuación administrativa unitaria del Estado se ejercite según reglas legales también unificadas para todo el territorio del Estado.

De cualquier forma, como dispone la Corte constitucional en esta misma decisión, la actuación subsidiaria del Estado debe estar revestida de determinadas garantías: Esa actuación debe respetar un parámetro de carácter sustancial (proporcionalidad y razonabilidad de la normativa estatal subsidiaria), y otro de carácter formal, con el objeto de preservar el principio de colaboración leal constitucionalmente previsto en el art. 120 de la Constitución: El Estado puede actuar más allá de sus competencias propias sólo si ha intentado lograr un acuerdo (intesa) con el ente territorial invadido (que serán en todo caso las regiones cuando se trata de competencias legislativas, ya sean exclusivas de éstas o bien concurrentes); o si la ley correspondiente prevé instrumentos para garantizar la colaboración leal y el acuerdo entre el Estado y el ente regional en el ámbito de las actuaciones reglamentarias y de ejecución que se contemplen en la norma legal (así, por ejemplo, en la Sentencia 219 de 2005).

Desde este punto de vista, la falta de previsión, en la ley estatal dictada conforme al ejercicio de la competencia subsidiaria, de un procedimiento de concertación entre el Estado y la región para el ejercicio de las funciones administrativas que se contemplen en la ley, conlleva la inconstitucionalidad de la misma. Por su parte, una vez que la ley ha previsto esos mecanismos de con- 
certación, la falta de acuerdo entre el Estado y la región impediría la aplicación efectiva de la ley y el ejercicio de las funciones sustitutivas de carácter administrativo en él contempladas.

La preceptividad de ese acuerdo ha sido afirmada por la Corte constitucional en varias decisiones (además de la 303 de 2003, también en las sentencias $6,27,43$ y 233 de 2004). En todo caso, la duda que se suscita en sede doctrinal es si ha de tratarse, en una terminología tradicional en el ámbito constitucional italiano, de un acuerdo en sentido fuerte (supuesto en el cual la falta de acuerdo sería un obstáculo insuperable para concluir el procedimiento sustitutivo), o bien sería suficiente un acuerdo en sentido débil (donde el intento de lograr el mismo sería condición necesaria y suficiente). De cualquier forma, en una Sentencia muy reciente (la 151 de 2005), la Corte ha variado esta posición y ha admitido que el Estado pueda ejercer una función legislativa subsidiaria, aunque no se preserve el preceptivo acuerdo con el ente cuyas competencias son invadidas.

Pero hay otros supuestos en los que el Estado puede actuar más allá de sus propias competencias. Así ocurre cuando éste ejerce los poderes sustitutivos previstos en el art. 120.2, según el cual el Gobierno puede reemplazar a los órganos de las regiones (y del resto de entes territoriales subestatales) en situaciones fisiológicas (en el caso de la sustitución ejercida cuando lo demanden "... la tutela de la unidad jurídica o de la unidad económica y en particular la tutela de los niveles esenciales de las prestaciones relativas a los derechos civiles y sociales...»), y también en situaciones patológicas ("... ante el incumplimiento de las normas y de los tratados internacionales o de la normativa comunitaria..." por parte de los entes territoriales subestatales).

Ambos son supuestos extraordinarios en los que sólo corresponde al Estado la capacidad para reemplazar a otro ente territorial, pero los casos en que caben actuaciones sustitutivas no se agotan con lo dispuesto en este precepto. La Corte ha admitido que existen también supuestos de sustitución ordinaria que pueden ser ejercidos tanto por el Estado como por las regiones. Estas últimas, cuando legislan sobre sus propias materias y definen una actuación de carácter administrativo de los entes locales, pueden determinar a su vez mecanismos de sustitución cuando dichos entes no cumplan con sus funciones (Sentencia 43 de 2004, entre las más recientes).

En cuanto a las sustituciones extraordinarias fisiológicas que son exclusivas del Estado, las mismas se justifican en garantizar la unidad jurídica o económica en su seno, pero también en la tutela de los niveles esenciales de las prestaciones relativas a los derechos civiles y sociales (o, en otras palabras, la garantía de una igualdad esencial en el disfrute por los ciudadanos de todo tipo de derechos, en su dimensión prestacional). Desde esta perspectiva, en la Constitución italiana se distingue entre la tutela de esos niveles esenciales, que se configura como presupuesto habilitante de la actuación sustitutiva del Estado, y la determinación de dichos niveles (de la igualdad esencial en el disfrute de los derechos), que se configura en la Constitución como una de las competencias exclusivas del Estado [art. 117.1, m)]. 
En ambos casos, quedaría bastante definido el alcance propio de cada uno de estos preceptos de la Constitución italiana que se refieren a la preservación de la igualdad básica de derechos entre los ciudadanos; y también la actuación que corresponde al Estado con base en cada uno de ellos. Algo bien diferente, puede decirse, a lo que ha ocurrido en nuestro ordenamiento jurídico a partir de las previsiones del art. $149.11 .^{\circ}$ y del art. 139.1 de la Constitución, como se ha demostrado en la jurisprudencia del Tribunal Constitucional sobre el alcance normativo de esos preceptos y sobre las competencias (o mejor, facultades de actuación) que corresponderían al Estado a partir de los mismos.

\section{LAS MATERIAS COMPETENCIALES TRANSVERSALES}

Respecto de la configuración de la determinación (o regulación, según la terminología de la Constitución española) de los niveles esenciales (o de las condiciones básicas, $i d$.) como una materia competencial, la Corte constitucional italiana ha considerado que "... los niveles esenciales de las prestaciones relativas a los derechos civiles y sociales, no se trata de una "materia" en sentido estricto, sino de una competencia del legislador estatal adecuada para incidir sobre todas las materias, respecto de las cuales el propio legislador debe poder establecer las normas necesarias para asegurar a todos, sobre todo el territorio nacional, el disfrute de las prestaciones garantizadas como contenido de dichos derechos, sin que la legislación regional pueda limitarlas o condicionarlas" (Sentencia 282 de 2002).

Sin embargo, esta competencia no puede ser alegada por el Estado en relación con cualquier regulación relativa a los derechos de los ciudadanos constitucionalmente garantizados. Cuando se trata de la disciplina legal de las facultades de actuación que se derivan de dichos derechos para los individuos, sin que dicha disciplina se refiera a prestaciones vinculadas con el derecho en cuestión, el Estado podrá alegar otros títulos competenciales para legitimar su intervención, pero no el de la determinación de los niveles esenciales de las prestaciones relativas a los derechos civiles y sociales (Sentencia n. ${ }^{\circ} 271$ de 2005 de la Corte constitucional italiana, en cuanto a la privacy y a la protección de datos personales).

De cualquier forma, en este supuesto de la determinación de los niveles esenciales... nos encontraríamos con lo que se denomina en el ámbito de la doctrina y de la jurisprudencia constitucional italianas como materias no materias o, en una terminología que nos es más usual, como competencias transversales; competencias que no se circunscriben propiamente a un ámbito material definido, sino que se caracterizan por su capacidad para trasladarse horizontalmente en el ordenamiento, abarcando distintos espacios materiales. Eso es lo que explica la competencia del Estado para dictar normas en ámbitos que estarían reservados, en principio, a la legislación exclusiva o concurrente de las regiones, ya que este tipo de materias enunciarían una finalidad, más 
que circunscribir un determinado sector de la legislación estatal, entrelazándose así con competencias y espacios materiales atribuidos a la potestad legislativa regional.

La Corte ha afirmado que disponen de esta naturaleza de materias transversales la que se acaba de mencionar, pero también otras competencias del Estado como la tutela de la competencia (Sentencia n. ${ }^{\circ} 14$ de 2004), la tutela del medio ambiente (Sentencia n. 378 de 2003) o la tutela de la salud (Sentencia n. ${ }^{\circ} 282$ de 2002); las dos primeras competencias exclusivas de aquél, la última una competencia de carácter concurrente. En este sentido, llama la atención que la Corte constitucional haya configurado como competencias transversales aquéllas que se configuran en la Constitución italiana como actuaciones de carácter tuitivo atribuidas al Estado respecto de un determinado ámbito material, lo que justifica la posible intervención del mismo sobre las diferentes materias que pueden englobarse en ese ámbito y que podrían estar atribuidas constitucionalmente, en principio, a las regiones; y así ocurre, también, en el caso de la determinación de los niveles esenciales de prestación de los derechos, puesto que esta materia tiene la doble dimensión referida en cuanto a la actividad estatal que legitima [arts. 117.2, m) y 120.2, mencionados supra].

Como quiera que sea, esta legitimación del Estado para actuar competencialmente con arreglo a objetivos, incidiendo en el espacio de títulos competenciales que no le son propios, está sujeta a límites; la actuación estatal no puede comprimir el marco competencial de las regiones hasta dejarlo sin contenido. La Corte ha estado especialmente atenta a este problema cuando se ha ocupado de la tutela de la competencia y de las actuaciones de carácter económico del Estado que podrían ampararse bajo esa tutela.

El Alto tribunal italiano admite en la Sentencia n. 282 de 2002 que el Estado pueda llevar a efecto intervenciones públicas en el ámbito del mercado, incluidas las ayudas (que sean conformes con el ordenamiento comunitario) dirigidas a promover el desarrollo económico y la cohesión social; y considera legítimo que lo haga, incluso, en ámbitos que podrían vincularse con competencias de los entes regionales (sostenimiento de la innovación en los sectores productivos, industria y formación profesional...). Pero no puede hacerlo en cualquier supuesto, su actuación sólo estará justificada si se trata de políticas económicas que atañen al desarrollo del conjunto del país, al equilibrio económico general; el elemento determinante será la dimensión de los intereses que justifiquen la intervención pública, ya sea regional ya sea nacional.

Además, como ha considerado la propia Corte, la regla general en el ámbito de las intervenciones presupuestarias del Estado es que "... la constitucionalidad de las normas estatales que instituyen nuevos fondos está condicionada, por regla general, en cuanto a la competencia para dictarlas, a la inherencia de su destino a la financiación de obras y servicios incluidos en materias de competencia estatal. La dedicación de esa financiación a fines que entren en las materias de competencia residual de las regiones, o incluso en materias concurrentes, comporta la inconstitucionalidad de las normas estatales" (por ejemplo, en la Sentencia n. ${ }^{\circ} 231$ de 2005, entre las más recientes). 


\section{EL INTERÉS NACIONAL}

Pero ese parámetro de la dimensión de los intereses en juego que justificaría la legitimación de la intervención estatal a través de las competencias transversales (y también del principio de subsidiariedad y de los poderes sustitutivos), y que avalaría la atracción de determinadas competencias regionales al campo de actuación del Estado, ha suscitado la alerta entre la doctrina, ya que vendría a suponer, en último extremo, la reviviscencia del interés nacional previsto en la Constitución italiana hasta la reforma de 2001, que se había venido configurando a través de la jurisprudencia constitucional como límite a la actuación de los entes regionales y también como cláusula habilitadora para la intervención del Estado en el ámbito competencial de estas últimas.

Recuperación indirecta de un principio connatural a otra forma de organización territorial del poder ( más regional y menos federal) que se confirmaría por la similitud de los criterios definidos por la Corte para acotar la actuación estatal, a través de la subsidiariedad o de la transversalidad, con aquéllos delimitadores del interés nacional, esto es, la razonabilidad de los presupuestos que justifican la actuación estatal y la proporcionalidad de las medidas previstas en la misma. Y ello a pesar de la reiteración con la que la Corte ha afirmado, tras la reforma constitucional de 2001, que el principio de subsidiariedad no puede asumir "... la función que tenía en otro tiempo el interés nacional, cuya alegación autónoma no es ya suficiente para justificar el ejercicio por parte del Estado de una función de la que no sea titular con base en el art. 117 de la Constitución, (Sentencia n. 303 de 2003).

La trascendencia del principio del interés nacional en el reparto de competencias entre el Estado y las regiones característico del ordenamiento italiano, se pone de manifiesto no sólo en la jurisprudencia constitucional que se acaba de referir, sino también en el intento de recuperación de dicho principio que se contiene en la propuesta de reforma constitucional a la que venimos haciendo referencia. Pero, además, se pretende recuperar con un contenido que supondría un nuevo giro (en este caso menos federal) en la organización territorial del poder respecto de la orientación (más federal) que adopta la reforma constitucional de 2001. Para explicarlo mejor, parece adecuado referir brevemente cómo se preveía el principio del interés nacional, como límite a la legislación regional, en el texto de la Constitución italiana vigente hasta 2001.

En la teoría de la norma constitucional, dicho principio se configuraba como un limite di merito de la actuación regional; en definitiva, como un mecanismo de control político sobre la misma. A grandes rasgos, cuando el delegado del gobierno en la región consideraba que la ley regional contrastaba con los intereses nacionales, podía reenviar ésta al Consejo regional, que podía volverla a aprobar por mayoría absoluta. En ese supuesto, al Gobierno le cabían dos posibilidades si pretendía que la ley no fuese promulgada, impugnarla ante la Corte constitucional por posibles vicios de inconstitucionalidad, o bien hacerlo ante el Parlamento italiano si se alegaban vicios de mérito (vulneración de los intereses nacionales). 
En la experiencia práctica, el Gobierno no llegó a impugnar leyes regionales por conflicto de intereses ante las Cámaras nacionales, y el límite del interés nacional se fue transformando de limite de mérito en límite de constitucionalidad de dichas leyes. En lo que una parte de la doctrina consideraba una involución y otra una evolución de los presupuestos establecidos en la Constitución, la Corte admitió las impugnaciones de leyes regionales por el Gobierno, en las que se alegaba la inconstitucionalidad de las mismas por contravenir el interés nacional (entre las más relevantes al respecto, la Sentencia n. ${ }^{\circ} 177$ de 1988).

Eso trajo como consecuencia que la Corte tuviera que conocer de cuestiones (de carácter político) para las que no era, en principio, competente (lo cual podía considerarse una involución, puesto que se acrecía el canon de valoración jurisdiccional de las leyes regionales, a la vez que éste se hacía menos cierto); pero se eliminaba, en la práctica, la valoración de las leyes regionales por un órgano político y según criterios políticos (lo cual podía considerarse como una evolución, puesto que ese control político se basaba en la superioridad jerárquica del Estado sobre las regiones).

En cualquier caso, como se ha señalado en anteriores crónicas, una de las aportaciones fundamentales contenidas en la reforma constitucional de 2001 ha sido la derogación de ese tipo de controles políticos previstos en la Constitución italiana; además, eso ha conllevado que el interés nacional deje de ser también un limite de constitucionalidad (no sólo de mérito) de la legislación regional ("... no se puede invocar la permanencia de un "interés nacional" como límite, implícito pero imprescindible... Una categoría de ese tipo es ajena al diseño constitucional vigente", Sentencia n. ${ }^{\circ} 370$ de 2003).

\section{ALGUNO DE LOS CONTENIDOS DE LA PROPUESTA DE LEY CONSTITUCIONAL DE REFORMA}

Sin embargo, la propuesta de reforma constitucional que se tramita en la actualidad en el Parlamento italiano recupera la cláusula del interés nacional; pero no lo hace propiamente como cláusula de garantía de unidad que legitimaría la actuación del Estado sobre determinadas materias, sino que se incorpora como cláusula de control político sobre la actuación regional. Según lo allí previsto, el Gobierno puede alegar el interés nacional frente a una ley regional (o parte de la misma), instando a la región implicada a remover las disposiciones legales consideradas perjudiciales para dicho interés. En el caso de que la región no modifique o derogue esas disposiciones, el Gobierno somete la cuestión al Parlamento reunido en sesión conjunta, que puede decidir la anulación de la ley por mayoría absoluta.

Ciertamente, son este tipo de cláusulas las que acaban por definir una determinada forma de gobierno como regional o como federal, más allá de los concretos títulos competenciales que se atribuyan al Estado o a los entes subestatales en los listados constitucionales. Por eso, el espíritu de la propuesta de 
ley constitucional no puede valorarse únicamente a partir del reequilibrio competencial que prevé, introduciendo la categoría y el listado de competencias exclusivas de las regiones (hasta ahora éstas vienen determinadas de manera residual), o atribuyendo nuevas competencias al Estado (ámbito de la propuesta que ha sido el más valorado por la doctrina, al configurar como competencias exclusivas de aquél, con base en la dimensión nacional o estratégica de determinados sectores, nuevas materias y otras que tienen en el texto constitucional vigente el carácter de concurrentes).

Desde este punto de vista, no parece fácil concluir que el texto constitucional resultante de las modificaciones propuestas por la actual mayoría parlamentaria aporte una mejora efectiva del Estado regional italiano. En primer lugar, no ha habido tiempo, aún, para que la reforma vigente pueda consolidarse por vía jurisprudencial o legislativa. En segundo lugar, no parece factible que una Constitución pueda realizar una enumeración de títulos competenciales completa o carente de zonas grises, puesto que su delimitación es fruto de consensos, negociaciones y acuerdos donde las transacciones han de primar, a menudo, sobre la perfección técnica.

Por lo demás, si estas imperfecciones son imputables al texto constitucional de la reforma de 2001, también podrían serlo al texto constitucional propuesto en la actualidad. No en balde, éste tiene su origen en una mayoría de gobierno que engloba a partidos confederalistas y a partidos centralistas, que defienden planteamientos claramente divergentes en cuanto a la autonomía que ha de corresponder a las regiones y que han defendido con anterioridad sus propias propuestas de reforma constitucional.

Esto es lo que explicaría que en la propuesta presentada finalmente por el Gobierno se prevean, por ejemplo, títulos competenciales exclusivos del Estado y otros concurrentes que son definidos de modo muy similar; o que las competencias legislativas exclusivas de las regiones vengan determinadas a través únicamente de cuatro títulos materiales específicos (asistencia y organización sanitaria, organización de la enseñanza básica, definición de los programas escolares y formativos de interés regional, policía administrativa regional y local) y de una cláusula residual general (cualquier otra materia no reservada a la legislación del Estado), con los problemas hermenéuticos que de ahí pudieran derivarse.

En tercer lugar, es lógico que la inauguración de una nueva forma de organización territorial del poder conlleve, en sus inicios, una mayor litigiosidad; y que pueda parecer, a su vez, que las cláusulas de garantía de la unidad del sistema (normativo, económico, social, de derechos) no son suficientes para anteponer la intervención garantista del Estado a las tendencias centrífugas y diversificadoras (pero no necesariamente disgregadoras) que toda descentralización política intensa conlleva. Pero la Corte constitucional italiana, como vienen haciendo por regla general, de manera certera y efectiva, los altos tribunales de los estados descentralizados, está logrando mantener la unidad del sistema con los criterios hermenéuticos de los que dispone el texto constitucional vigente (que no son pocos, como se ha dicho). 
Por estas razones, parece que el principal cometido que hubiera correspondido a una nueva modificación constitucional, por lo que se refiere a la organización territorial del poder, hubiese sido más bien el de completar aquellas cuestiones que no quedaron cerradas en la anterior reforma; sobre todo, y de manera principal, los mecanismos y los espacios de concertación entre el Estado y las regiones, y los procedimientos y las sedes para que éstas intervengan en la adopción de decisiones estatales. La propuesta de reforma a la que nos venimos refiriendo se ocupa de manera extensa de estas cuestiones, a través de la reformulación del Senado (como Senado federal) y de los procedimientos legislativos estatales, y a través de la constitucionalización de la cooperación interadministrativa (Conferencia Estado-regiones).

Si la propuesta de modificación constitucional prospera, habrá ocasión de referirse en sucesivas crónicas a estos contenidos de la misma. Baste con señalar ahora, para concluir, que la impronta federal que se pretende dar al Senado en esta propuesta, a través de la competencia preferente que se le asigna en el procedimiento de aprobación de las leyes marco estatales en las materias concurrentes, y a través de la designación de los senadores en cada región, por sufragio universal y directo, de manera simultánea a las elecciones del Consejo regional, ha sido considerada por la doctrina más solvente como una organización funcional y electiva del Senado alejada de los estándares habituales de las federaciones. Pero como se decía al principio de esta Crónica, ese análisis detallado se corresponde mejor con una propuesta de reforma aprobada definitivamente y en vigor (Constitutione data). 